\title{
SOCIAL RESPONSIBILITY IN FOOD INDUSTRY
}

\author{
Luminița-Mihaela Dumitrașcu', Dumitru-Florin Moise ${ }^{2}$ \\ ${ }^{1}$ The Bucharest University of Economic Studies, Accounting nd Audit Department Faculty \\ of Accounting and Management Informatic Systems, Bucharest, Romania \\ ${ }^{2}$ Timac-Agro, Bucharest, Romania \\ Mihaela.dumitrasu@cig.ase.ro \\ Moisedumitruflorin@yahoo.com
}

\begin{abstract}
There are many different front-of-pack nutrition labels and there is not yet established a convergence. Governments and manufacturers try to provide more nutritional information on food labels. The analysis covered the period between 1980 and 2021. This study increases the attention of all stakeholders involved in the front-of-pack nutrition labelling debate. In this regard is relevant to present the advantages and disadvantages, the similarities and the differences of front-of-pack nutrition labelling, because each one is unique, so it is hard to compare them by using the same criteria. The paper brings into the spotlights different policies from different countries that aim to educate the consumers about the content of food, the case of front-of-pack food labeling, that represents a social responsibility issue, especially for health and obesity prevention, noncommunicable diseases, cardiovascular diseases, cancer, diabetes, due to the important role played. Our results show that there are key items, in terms of social responsibility, companies should take into account when planning their strategies and may help also the investors in food manufacturing companies with an increased interest in social information to request and understand the importance of the front-of-pack nutrition labelling of companies they want to invest in. Our research is important for the business to advance in disclosure on the pack of food of relevant information, as well for the academic community regarding the front-ofpack nutrition labelling, as a responsibility issue. Future research is needed since there is a variety of front-of-pack nutrition labelling and is changing constantly.
\end{abstract}

Keywords: social responsibility, food labels, front-of-pack food labeling, regulations

JEL Classification: M14, L66

\section{Introduction}

Overweight and obesity rates have grown rapidly in England, Mexico, and the United States since the 1990s. Obesity is a growing problem resulting from different factors including social, individual, environmental ones (Ogden et al., 2006; Draper et al., 2013). Obesity conducts to increased risks for different chronic diseases, such as heart disease, cancer, diabetes (Kim and Popkin, 2005; Flegal et al, 2012). The availability of processed food is one of the main drivers of obesity and non-communicable diseases (Monteiro et al, 2012; Swinburn et al, 2011). In 2015, across the OECD (2017), $19.5 \%$ of the adult population was obese. This rate ranges from less than $6 \%$ in Korea and Japan to more than $30 \%$ in Hungary, New Zealand, Mexico, and the United States. More than one in four adults is obese in Australia, Canada, Chile, South Africa, and the United Kingdom. Over the past decade, the prevalence rate of overweight and obesity has increased in Canada, France, Mexico, Switzerland, and the United States, while it has stabilized in England, Italy, Korea, and Spain. There is, however, no clear sign of retrenchment of the epidemic, in any country, and one in six children is obese.

The objective of the present paper is to compare the existing front-of-pack nutrition labelling, to increase the understanding of their use. In this way, we provide knowledge in terms of 
front-of-pack nutrition labelling, and also the transparency increases. Our research is important for the business to advance in disclosure on the pack of food of relevant information, as well for the academic community regarding the front-of-pack nutrition labelling, as a responsibility issue.

The paper is divided into 5 sections. Section 1 provides a literature review on the impact of food labeling regulations, section 2 provides information related to features of the front of pack food labeling, section 3 comprises the methodology, section 4 refers to results, discussions, and issues related to sustainability, personal and social responsibility and the way we are free to choose what to eat and the last section presents conclusions, recommendations, and future research directions.

\section{Literature review on the impact of nutrition labeling regulations on food markets}

US Food and Drug Administration (US FDA) educates the public on trans fat-free foods. The Nutrition Labeling and Education Act (NLEA) implemented in 1994 required to disclose on the packages calories, fat, cholesterol, sodium, carbohydrates, fibers, sugar, protein, vitamins, minerals. NLEA regulated also the voluntary use of some claims such as sugarfree, gluten-free, low fat. Researchers have been interested in the impact of the NLEA policy on product consumption (Caswell and Padberg, 1992; Zarkin and Anderson, 1992).

In Australia, food labeling standards are established by the Australia New Zealand Food Standards Code (Wang et al, 2016). To avoid bad nutrients, consumers read the nutrition labels of the products. Some researchers discovered that salad dressing has a high-fat level. Other researchers found that consumers understand food content (Ippolito and Mathios, 1994; Marietta et al., 1999). There are studies in Australia that demonstrated the negative impact of obesity on the human body. One quarter of osteoarthritis and diabetes and onefifth of cardiovascular disease, colorectal, kidney, breast, uterine cancers have as the main cause the obesity. The problem is obesity rates rise also in children. The answer to obesity could be social responsibility or maybe personal responsibility. When implementing front of pack labeling we encourage healthier eating, but also some companies can have a decrease in revenues, due to the impact on purchasing. To prevent obesity we should implement both personal and social responsibility, such as governmental policies (Handsley et al, 2009; Brownell et al, 2009; Goetzel and Ozminkowski, 2008).

Some authors reported that European legislation on nutrition helps consumers to choose wisely (Leathwood et al., 2007). Balcombe et al. (2010) discovered that UK consumers pay more to avoid foods with "red" nutrients. Barreiro-Hurlé et al. (2010) discovered that nutrition information influences the consumption of healthy foods, while other researchers discovered that the consumption of healthy food is not influenced by nutrition labeling (Mojduszka et al., 2001).

In November 2006 the Australian Food and Grocery Council AFGC launched the voluntary labeling named Daily Intake Labelling, used by 180 brands, that inform consumers regarding the sugar, energy, carbo, protein, fat, saturated fat, sodium per serve in a monochrome format.

\section{Methodology}

The objective of the research is to present the history of front-of-pack-food labeling at the global level, which represents a social responsibility issue, in pandemic times. We realized this by conducting a literature review and by studying also the rules and regulations related to food systems, at the global level. In this regard, we try to determine if FOPNL received attention over time. (Table 1) 


\section{Tabel 1. Items used to describe FOPNL}

\begin{tabular}{|l|l|}
\hline Item & Description \\
\hline Category & $\begin{array}{l}\text { FOPNL are developed for categories of products } \\
\text { or a selection of products from a category }\end{array}$ \\
\hline Component & $\begin{array}{l}\text { FOPNL take into consideration the negative } \\
\text { components of products, while the others take } \\
\text { into account the positive components }\end{array}$ \\
\hline Reference unit & $\begin{array}{l}100 \mathrm{~g}, 100 \mathrm{ml}, 100 \mathrm{kcal} / \mathrm{KJ} \text { serving, reference } \\
\text { intake per day }\end{array}$ \\
\hline Objective & $\begin{array}{l}\text { To help consumers improve their healthy } \\
\text { choices, to stimulate the production of healthy } \\
\text { food }\end{array}$ \\
\hline Driver & Commercials, Government, NGO \\
\hline The tone of the voice & There are negative, positive, mixed FOPNL \\
\hline Use & Voluntary or mandatory \\
\hline Initiative & Public or private \\
\hline
\end{tabular}

Source: Authors' projection, based on documentation

The research is focused on FOPNL implemented at the national level, not on ones used by different retailers (Figure 1).

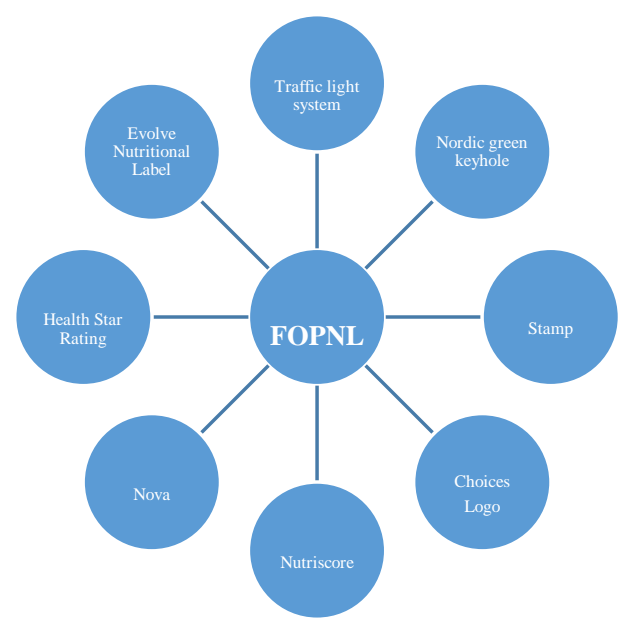

Figure 1: FOPNL implemented worldwide

Source: Authors' own research, based on documentation

After analyzing the literature on FOPNL we discovered there are some key issues to take into account when we start to compare the FOPNL

\section{Results and discussions}

Within this paper we investigated the regulations that exist worldwide to motivate consumers to eat healthier products. Manufacturers display voluntarily FOPNL nutrition information. According to the literature review carried out, we discovered that the first initiative of FOPNL 
was in 1980 when started action on salt. In 1989 was introduced the keyhole in Sweden, a voluntary health logo. In 1992 Slovenia launched the protective food logo. In 1993 high salt warning label and protective food logo was introduced. In 1998 healthier choice symbol was introduced in Singapore. In 2000 Finland launched the heart symbol. In 2004, UK, South Korea, Ecuador there is a color-coded labeling system, called the traffic light system that highlights the nutrition content of foods and drinks. Red light means high in fat, sugar, salt, amber means medium and green means low and a healthier choice. There are also labeling that mix red, amber, and green. It is better to use a single color labeling, to not confuse the customers. Under UK traffic light label, launched by the Food Standards Agency, which is voluntary, an amber light is medium, a green light is considered a healthy choice, and a red light must be used with moderation. The system discloses each nutrient as a percentage of the daily recommended intake (DRI). In 2005 heart tick was launched in Nigeria. In 2006 in Australia, the DIG Daily Intake Guide of the FOPNL system was launched. In the same year, UK improved the FOPNL, by implementing it for five nutrients (calories, sugar, fat, saturated fats, salt) renamed Reference Intakes label, the scheme being used across the EU. In 2007 Healthy choices was launched in Belgium and the Nordic green keyhole logo was developed by the Swedish National Food Agency, introduced first in Sweden, in 1989. It represents a food label and has a set of criteria for 33 product groups. In 2009, Denmark Norway Sweden, Iceland, Lithuania implemented the keyhole logo (for sugar, salt, fats, fiber, wholegrain), a voluntary manner, being free of charge label, and unused for low nutritional value products such as drinks and snacks. Netherlands choices logo has two choices stamps: green stamp (the healthy one, for bread, milk, fruits, vegetables), and blue stamp (for soups, sauces, snacks, or food containing artificial sweeteners). In 2008 Poland introduced the Healthy Choices logo. In 2011 was launched EU Regulation No 1169/2011 on Food Information to Customers (FIC). Us Facts Upfront a private initiative was published in January 2011, launched by Food Marketing Institute (FMI) and Grocery Manufacturers Association (GMA), to display calories, saturated fats, fats, sodium, sugar content, fiber, protein, potassium, vitamin $A$, vitamin $C$, vitamin $D$, calcium, iron, in a voluntary manner, per serving. The date of implementation was 2012. In 2011, Canada FOPL Clear on Calories Initiative was launched by The Canadian Beverage Association. Also, in 2011, in Thailand FOPL for energy, sugar, fat, sodium guideline daily amount was launched. In the same year, Czech Republic launched the Healthy Choices logo. In 2011 South Korea introduced the traffic light system. In 2012 EU introduced the FOPNL, which came into force starting on 31 December 2014. In 2012, in Malaysia, voluntary FOPNLs for energy, protein, carbohydrates, and fat were launched by the Malaysian Minister of Health. In 2013, the keyhole symbol was launched also in Iceland and Lithuania. In 2013, in UK and Ireland, the traffic light system and the recommended daily intake were launched. In 2014 EU FIC entered into force. In 2014 health star rating system in New Zealand and Australia was implemented. The health star rating is a rate from $1 / 2$ to 5 stars, based on energy, saturated fat, sugar, salt, sodium, fiber, and it is voluntary. The Australian Health Star Rating System is a 10 points indicator. In 2015, multiple traffic light system was launched in Portugal. In 2015, in Croatia, a healthy living guarantee mark was introduced. In 2016, EU countries start introducing country of origin labeling requirements (for example Italy, Spain, Greece, France, Romania, Portugal). In June 2016, in Chile were introduced front of pack labels, that announced when a negative nutrient exceeds the limit set by the Chilean Ministry of Health. In December 2016, as a part of its Healthy Eating Strategy, Canada launched a public consultation on a new compulsory food labeling logo that will warn about "high in sodium, sugars, and saturated fat" contents. Starting with December 2022, new rules will come into place. Will be multilingual FOPNL, calories will be bold and larger, vitamins will be expressed in $\mathrm{mg}$ and \% in daily intakes, like a footnote, daily value for sugars, list of minerals of health control, such as potassium, calcium, iron, the serving size, the font size of serving size and calories increased and bold line added under the calories information, titles contains and ingredients will be bold, 
allergens are included in contains, each ingredient begins with a capital letter, all of the sources of sugars are enumerated into brackets, on a neutral background, white. In 2017, six multinational companies developed Evolved Nutrition Label based on Reference Intake label and adding colors red to green, expressed per serving/portion. In 2017 in Korea a regulation requires manufacturers to inform the customers about the monosaccharides, disaccharides, and nutrients. In March 2017, an EU regulation introduces an easy to read FOPNL traffic light system. The Nutri-score is implemented in more than 110 large and small companies in January 2019 from France and was adopted also in Belgium and Spain. Nutri score is based on 15 scientific publications and is introduced in Luxembourg in February 2020. In 2017 Belgian Government voluntarily adopted the Nutri Score label, with implementation starting with 2018. On August 29, 2018, Uruguay was approved Decree $272 / 2018$ referring to FOPNL for those products containing excess amounts of dangerous ingredients (sugar, salt, fats) that is force starting with February 29, 2020. It prohibits also disclosure of persuasive elements, gifts, contents, games that could attract children and other consumers. In 2018, Nutriscore was introduced in Spain, and in 2019 in Portugal. Brasil, in 2019, adopted the NOVA food classification system, referring to the level of processing and groups foods into four categories, the first group (green color coding, unprocessed or minimally processed), the second group (yellow color coding, processed culinary ingredients), the third group (orange color-coding, processed foods), the fourth group (red color-coding, ultra-processed foods, and drinks). In 2020 Germany adopted Nutri Score. In January 2020, in Mexic, the Government published some amendments to NOM 051 SCFI SSA1-2010, related to FOPL. This affects the use of black octagonal seals and avoids the use of any celebrity, cartoon, or mascot image on products. The rule entered into force on April 2021.

\section{Front-of-pack nutrition labelling, a social responsibility issue}

Due to the changes, the EU intends to harmonize FOPNL before December 2022.

The European Commission has a proposal to harmonize the mandatory FOPNL and to make the food systems healthy, fair, environmentally friendly, and sustainable. According to articles number 30 to 34 of the Regulation Number 1169/20112 The Food Information to Consumers ( EU FIC) all prepacked food from the EU market should wear nutrition information, that includes the energy value, the amounts of sugars, salt, protein, saturated fat, carbohydrate, all expressed per $100 \mathrm{ml}$ or $100 \mathrm{mg}$, presented with the numbers aligned or in a tabular format. According to article number 35 of the Regulation Number 1169/2011 The Food Information to Consumers (EU FIC), to ensure that consumers are properly informed to make healthy choices they allow additional and redundant information in terms of energy value and amount of nutrients expressed in $200 \mathrm{~g}$, and/or using graphical symbols. The information disclosed should be fair, true, objective, to not create discrimination or limits to the free movement of products and goods.

Since European Commission considers color-coding the most promising in improving healthy choices, concludes that till the end of 2022 should introduce a harmonized mandatory FOPNL. Seven European countries (Italy, Czech Republic, Cyprus, Greece, Hungary, Latvia, and Romania) agree the labels should provide this information on the individual nutrients comprised within a product. There are also some exemptions, such as single ingredients products, traditional ones, protected origin products. They also agree that it should be taken into account the daily intake, to not avoid some products that are consumed in a small amount, such as oil. This position is oxymoronic with another scheme, Nutri Score, implemented by France, Spain, Belgium, Germany, Netherlands, and Luxembourg.

Brexit and UK exit from the EU represents an opportunity to introduce mandatory regulation for food labeling. An EU FOPNL scheme can promote social responsibility and sustainability, 
and also healthy eating. When we choose a product we are checking the price, if we like the taste, the image or the color of the package, nutritional value, but nothing about environmental impact. The food industry produces global greenhouse gas emissions, so to reduce the environmental impact, many changes are expected. In this regard, the European Commission indicated that they work for a harmonized FOPNL

\section{Conclusions}

In the light of the last changes in the FOPNL to harmonize them across the world, the current research realized a comparison between the FOPNL existing worldwide. Most studies from literature on FOPNL are based on experiments regarding the FOPNL impact on purchasing and consumption. Current global health policy results in a variety of different FOPL systems. Studies reveal, through an online experiment, that Nutriscore could be the FOPNL that could be implemented worldwide (Egnell et all, 2020). There is a debate at the global level for setting additional systems and maybe a global one, that is harmonized. All developments and regulations and World Health Organisation recommendations contribute to changes in FOPNL systems. Organizations should develop marketing and social responsibility strategies to keep current with the regulatory system. They should adapt their products to future needs and identify challenges and opportunities in directing customers to choose a healthy diet and to eradicate confusion or temptations.

FOPNL provides plenty of information and the food industry tries to convince people and governments about the fact that there is no unhealthy food, but there are only unhealthy diets, due to personal responsibility, not to on social responsibility. Governments are unable to fight with the food industry and to provide real and effective nutritional information in a format easy to understand and to interpret, a homogeneous format, to sustain people to choose healthily. Thus, introducing other measures, rules, regulations, and codes to combat obesity does not look well.

Many FOPL are interpretative, depending on access to fresh food, environmental factors, poverty, limited resources, and family size. One food labeling solution could be represented by a design that increases the capacity of individuals to adopt informed dietary choices, the packaged food should display the nutritional information per both $100 \mathrm{~g} / 100 \mathrm{ml}$ and recommended serving, in each country should be developed a Food Standard Code. Even if some individuals declare that they are immune to food advertising that is not a solution. An argument is represented by the number of money companies invest in food advertising (Scully et al, 2009).

One of the limits in implementing healthy food is represented by a low-profit margin, due to the price of the product. A solution in implementing the FOPNL system, as an item of social responsibility is represented by lifestyle medicine. Different policies improve the health of the people, for the prevention of smoking, chronic disease, obesity. To reduce calories, we need to change eating patterns, the level of physical activity, the nutritional quality of the food, reducing sugar, salt, and fat consumption, increasing vegetable consumption.

The European Commission launched the Farm to Fork strategy, in May 2020, which proposes a harmonized and mandatory FOPNLsystem with implementation by the end of 2022. All the obstacles should be passed because it is important to improve the health of consumers to reduce the burden of non-communicable diseases. This represents a critical issue nowadays given the high risk of people that have the non-communicable disease, overweight, obesity, or other comorbidities associated with covid 19 infections. 


\section{References}

1.Andriessen, D. (2006). On the metaphorical nature of intellectual capital: a textual analysis. Journal of Intellectual Capital, 7(1), 93-110.

2.Aldag, R.J., \& Stearns, T.M. (1991). Management (2 ${ }^{\text {nd }}$ ed.). Cincinnati, OH: SouthWesternPublishing.

3.Barnes,B.R.,Leonidou,L.C.,Siu,N.Y.M.,\&Leonidou,C.(2010).Opportunismasthei ibiting trigger for developing long-term-oriented Western exporter - Hong Kong importer relationships.JournalofInternationalMarketing, 18(2), 35-64.

4.Barroso, J.M.D. (2013). Speech by President Barroso on the outcome of the European Council meetingontheMultiannualFinancialFrameworkof7 http://europa.eu/rapid/press-release SPEECH-13130 en.htm. -

5.Bratianu, C. (2011a). Changing paradigm for knowledge metaphors from dynamics to thermodynamics. System Research and Behavioral Science, 28, 160169.

6.Bratianu, C. (2011b). A new perspective of the intellectual capital dynamics in organizations. In Vallejo-Alonso, B., Rodriguez-Castellanos, A., Arregui-Ayastuy, G. (Eds.). Identifying, measuring, and valuing knowledge-based intangible assets: new perspectives (pp. 1-21). Hershey, PA: IGI Global.

7.Bratianu, C. (2013). The triple helix of the organizational knowledge. Management Dynamics in the Knowledge Economy, 1(2013), 207-220.

8.Ernst\&Young(2011). The sustainability revolution.Excellencein sustainability reporting awards2011.Retrieved from http://www.ey.com/ZA/en/Services/Specialty Services/Climate-Changeand-Sustainability-Services/2011---ESR---Main-Page.

9.Brownell K, Horgen K. (2007). Food fight: The inside story of the food industry,

America's obesity crisis, and what we can do about it. McGraw-Hill; New York.

10.Brownell, K. D., Farley, T., Willett, W. C., Popkin, B. M., Chaloupka, F. J., Thompson, J. W., \&

11.Ludwig, D. S. (2009). The public health and economic benefits of taxing sugar sweetened beverages. The New England journal of medicine, 361(16), 1599-1605. https://doi.org/10.1056/NEJMhpr0905723

12.Barreiro-Hurlé,J, Gracia,A, de-Magistris, T, (2010), Does nutrition information on food products lead to healthier food choices? Food Policy, 35 (3), pp. 221-229, http://dx.doi.org/10.1016/.j.foodpol.2009.12.006

13.Balcombe, K, Fraser, I, Falco, SD. (2010). Traffic lights and food choice: a choice experiment examining the relationship between nutritional food labels and price Food Policy, 35, pp. 211-220

14.Caswell, JA, Padberg, DI, 1992. Toward a More Comprehensive Theory of Food Labels, American Journal of Agricultural Economics, Agricultural and Applied Economics Association, vol. 74(2), pages 460-468.

15.Draper,A, Adamson, A, Clegg,S, Malam, S, Rigg, M, Duncan, S, (2013). Front of-pack nutrition labeling: are multiple formats a problem for consumers? Eur. J. Pub. Health, 23 (2013), pp. 517-521

16.Egnell, M., Talati, Z., Galan, P., Andreeva, V. A., Vandevijvere, S., Gombaud, M., Dréano-Trécant, L., Hercberg, S., Pettigrew, S., \& Julia, C. (2020). Objective understanding of the Nutri-score front-ofpack label by European consumers and its effect on food choices: an online experimental study. The international journal of behavioral nutrition and physical activity, 17(1), 146. https://doi.org/10.1186/s12966-020-01053-z

17.Flegal, K. M., Carroll, M. D., Kit, B. K., \& Ogden, C. L. (2012). Prevalence of obesity and trends in the distribution of body mass index among US adults, 1999 2010. JAMA, 307(5), 491-497.

18.Gibson, A.; Edgar, J.D.; Neville, C.E.; Gilchrist, S.E.C.M.; McKinley, M.C.; Patterson, C.C.; Young, I.S.; Woodside, J.V. (2012). Effect of fruit and vegetable consumption on immune function in older people: A randomized controlled trial. Am. J. Clin. Nutr., 96, 1429-1436.

19.Goetzel RZ, Ozminkowski RJ. (2008). The health and cost benefits of work site health-promotion programs. Annu Rev Public Health.;29:303-323. doi:10.1146/annurev.publhealth.29.020907.090930 20. Handsley, E., Mehta, K., Coveney, J., \& Nehmy, C. (2009). Regulatory axes on food advertising to children on television. Australia and New Zealand health policy, 6, 1. https://doi.org/10.1186/17438462-6-1

21.Huang, Z.; Liu, Y.; Qi, G.; Brand, D.; Zheng, S. (2018). Role of Vitamin A in the Immune System. J. Clin. Med., 7, 258.

22.Huff, A.G.; Beyeler, W.E.; Kelley, N.S.; McNitt, J.A. (2015). How resilient is the United States' food system to pandemics? J. Environ. Stud. Sci., 5, 337-347 
23.Inchley J, Currie D, Young T et al (2016) Growing up unequal: gender and socioeconomic differences in young people's and well-being. Health Behaviour in School-aged Children (HBSC) study: international report from the 2013/2014

survey. WHO Regional Office for Europe. http://www.euro.who.int/en/health topics/Lifestages/child-and-adolescent-health/health-behaviour-in-school-aged children-hbsc. Accessed 06 August 2020

24.Ippolito, Pauline M. and Mathios, Alan D. (1994a), "Nutrition Information and Policy: A Study of U.S. Food Production Trends," Journal of Consumer Policy, M (Fall), forthcoming.

25.Ippolito, Pauline M. and Mathios, Alan D. (1994b), Information, Advertising and Policy, A Study of Fat and Cholesterol Consumption in the United States, Journal of Consumer Policy, M (Fall), forthcoming.

26.Kim, S., \& Popkin, B. M. (2005). Commentary: Understanding the epidemiology of overweight and obesity--a real global public health concern. International Journal of Epidemiology, 35(1), 60-67.

27.Leathwood, P. D., Richardson, D. P., Strater, P., Todd, P., \& van Tripp, H. (2007). Consumer understanding of nutrition and health claims: sources of evidence. British Journal of Nutrition, 98(3), $474 \mathrm{e} 484$

28.Joon Ho Lim, Rishika Rishika, Ramkumar Janakiraman, P.K. Kannan. Competitive Effects of Frontof-Package Nutrition Labeling Adoption on Nutritional Quality: Evidence from Facts Up Front-Style Labels. Journal of Marketing, 2020; 002224292094256 DOI: 10.1177/0022242920942563

29.Marietta, A. B., Welshimer, K. J. and Anderson, S.L.(1999).Knowledge, attitudes and behaviours of college students regarding the 1990 Nutrition Labelling Education Act food labels. Journal of American Dietetic Association, 99: 445-449

30.Monteiro CA, Cannon G. (2012). The impact of transnational "Big Food" companies on the south: A view from Brazil. PLoS Med.;9:e1001252.

31.Mojduszka, E.M., Caswell, J.A. and Harris, M. (2001), Consumer choice of food products and the implications for price competition and government policy, Agribusiness, Vol. 17 No. 1, pp. 81-96.

32.Naik, S.R.; Thakare, V.N.; Joshi, F.P. (2010). Functional foods and herbs as potential immunoadjuvants and medicines in maintaining healthy immune system: A commentary. J. Complement. Integr. Med., 7, 1.

33.Murphy B, Sanderson, J (2017) Soft law, responsibility and the biopolitics of front-of-pack food labels, Griffith Law Review, 26:3, 355-377, DOI: 10.1080/10383441.2017.1436371

34.Swinburn, B.A., et al. (2011) The Global Obesity Pandemic: Shaped by Global Drivers and Local Environments. The Lancet, 378, 804-814. http://dx.doi.org/10.1016/S0140-6736(11)60813-1

35.Ogden, CL, Carroll,MD, Curtin, L.R. McDowell, M.A. Tabak, C.J. Flegal K.M. 2006), Prevalence of overweight and obesity in the United States, 19992004 JAMA, 295, pp. 1549-1555

36.Péneau K.M. S, Buscail C, et al. Perception of different formats of front-ofpack nutrition labels according to sociodemographic, lifestyle and dietary factors in a French population: cross-sectional study among the NutriNet-Santé cohort participants. BMJ Open 2017;7:e016108. doi:10.1136/ bmjopen-2017-016108:

37.Scully, M., Dixon, H., \& Wakefield, M. (2009). Association between commercial television exposure and fast-food consumption among adults. Public Health Nutrition, 12(1), 105-110. doi:10.1017/S1368980008002012

38.Wang O, De Steur H, Gellynck X, Verbeke W. (2016). Motives for consumer choice of traditional food and European food in mainland China. Appetite.;87:143 151. doi:10.1016/j.appet.2014.12.211

39.Wang, L.; Wang, Y.; Ye, D.; Liu, Q. (2020). A review of the 2019 Novel Coronavirus (COVID-19) based on current evidence. Int. J. Antimicrob. Agents, 105948.

40.Woodside, J.V. (2012). Effect of fruit and vegetable consumption on immune function in older people: A randomized controlled trial. Am. J. Clin. Nutr., 96, 14291436.

41. Thakare, V.N.; Joshi, F.P. (2010). Functional foods and herbs as potential immunoadjuvants and medicines in maintaining healthy immune system: A commentary. J. Complement. Integr. Med., 7, 1 42.Wu, P.; Wang, X.; Zhou, L.; Tong, Y.; Ren, R.; Leung, K.S.M.; Lau, E.H.Y.; Wong, J.Y.; et al. (2020). Early Transmission Dynamics in Wuhan, China, of Novel Coronavirus-Infected Pneumonia. N. Engl. J. Med., 382, 1199-1207

43. Gary A. Zarkin and Donald W. Anderson, (1992), Consumer and Producer Responses to Nutrition Label Changes, American Journal of Agricultural Economics, 74, (5), 1202-1207 
The Annals of the University of Oradea. Economic Sciences

TOM XXX, $1^{\text {st }}$ Issue, July 2021

44. Zhou, P.; Yang, X.L.; Wang, X.G.; Hu, B.; Zhang, L.; Zhang, W.; Si, H.R.; Zhu, Y.; Li, B.; Huang, C.L.; Et Al. (2020). A Pneumonia Outbreak Associated with A New Coronavirus Of Probable Bat Origin. Nature, 579, 270-273 